\title{
Do Men and Women Estimate Property Values Differently?
}

\author{
Cheryl Doss, University of Oxford \\ cheryl.doss@qeh.ox.ac.uk \\ Zachary Catanzarite, Johns Hopkins University \\ Hema Swaminathan, Indian Institute of Management, Bangalore \\ William Baah-Boateng, University of Ghana \\ Carmen Diana Deere, University of Florida \\ Louis Boake-Yiadom, University of Ghana \\ Suchitra J.Y., Indian Institute of Management, Bangalore
}

\section{Forthcoming in World Development}

\begin{abstract}
Wealth data are typically obtained by asking respondents about the value of their key assets. Yet, what if the answers to valuation questions vary systematically depending on who is interviewed? Using nationally representative data from Ghana and Ecuador and for the state of Karnataka, India, we analyze whether men and women provide different responses to questions about the monetary value of their home. Using a DFL decomposition across the full sample and comparing the responses of husbands and wives in our couple sample, we find that overall, the distribution of monetary values reported by women tends to be narrower than that reported by men. This finding has implications both for data collection efforts and for measures of the gender wealth gap.

Acknowledgments: Funding for this work was received from the Vanguard Charitable Endowment Program. We are grateful to Gender Asset Gap Project team members Abena D. Oduro and Caren Grown for their inputs.
\end{abstract}

Keywords: housing, values, gender gap

JEL Codes: C81, C83, D31, J16 


\section{Introduction}

Globally, there is increasing interest in the role of assets and wealth as they relate to poverty and inequality. While traditional approaches to studying poverty and inequality have centered on income or consumption measures, recent research highlights the role of wealth in furthering the understanding of these issues (Davies, 2008). Studying the joint distribution of income and wealth is important from a policy perspective; it can help identify the most vulnerable groups or those most likely to experience consumption shortfalls or other forms of deprivation. ${ }^{1}$

Yet, there has been relatively little research to identify the best practices on collecting wealth data in household surveys. In fact, the first international set of guidelines for collecting data on household wealth was published only in 2013 (OECD, 2013). ${ }^{2}$ Wealth data are typically obtained by asking respondents about the value of their key assets. Yet, what if the answers to valuation questions depend on who is interviewed? For example, if men and women systematically report different monetary values for the same assets, then the resulting wealth distributions could look different, with implications for our understanding of wealth inequality.

Using detailed data from household asset surveys in Ecuador, Ghana, and Karnataka, India, this paper examines whether men and women respond differently to asset valuation questions, specifically those on housing values. This issue is analyzed in several ways. First, is there a difference by sex in the response rate on valuation questions? Second, is there a difference by sex in reported asset values? How do the attributes of housing affect the values reported and does this differ for men and women? We also explore whether the reported value of an asset differs across members of the same household. We analyze two samples; first, a sample of the person considered the most knowledgeable about assets in each household, and second, a couple sub-sample where both spouses reported separately about the same dwelling.

There are many reasons why men and women might provide different estimates of value. First, they may have varying relations with the market. Participation in specific asset marketssuch as those for land, housing, livestock, or consumer durables-may differ considerably for men and women. In some areas, particular markets — such as those for large animals — may be places where few women participate. Yet women may follow the prices in other markets-such as those for urban housing-more closely than men may. A second, related reason is that men and women may specialize within the household, each garnering information only on assets relevant to activities within their domain. Finally, the question that is typically asked in a household survey is what price would be received if the asset were sold. Given the gendered nature of property markets, men and women might receive different prices for the same property if they were to sell it. Thus, the patterns of estimated value might differ depending on whether men or women are interviewed. Depending on the type of asset, ownership patterns may vary across men and women. If owners are better informed about asset values than nonowners, one could expect differences between men and women's responses. Our data does not allow us to distinguish among these reasons, but they motivate why it is important to consider gender differences in reported values.

It is worth noting that all of the reported values are the respondents' perceptions of or expectations regarding the value of their dwelling. The actual price that might be received would depend not only on the characteristics of the dwelling, and those of the buyer and seller, but also on current market conditions and the length of time that the seller was willing to wait to conclude the sale. So even conceptually it is not possible to identify the true value in the abstract. Individuals' perception of their wealth will affect a myriad of decisions. Their willingness to take 
risks or invest in their children's education or their own enterprises, all may be influenced by their wealth. To the extent that men and women perceive the value of their assets, such as their dwelling, differently, this may shape the decisions they make.

In addition, evidence suggests that women's share of household wealth will affect their bargaining power and thus, the outcome of household decisions (Doss, 2006), although these studies have generally used proxy respondents, such as the household head, to report wealth for all household members. Women's empowerment or their bargaining power might thus be influenced by their perception of their wealth which may differ from their wealth as reported by their spouse.

Our research makes several important contributions. We add a wealth dimension to the literature that explores how the sex of the respondent affects survey responses. Studies on labor force participation (Bardasi, Beegle, Dillon and Serneels, 2011), income (Fisher, Reimber and Carr, 2010), and financial information (Fletschner and Mesbah, 2011) suggest that responses may differ depending on who within the household is interviewed. To the best of our knowledge, this is the first paper that examines how reported asset values differ based on the sex of the respondent. We also contribute to the nascent discussion on the best practices for collecting asset ownership information (Doss, Grown, and Deere, 2008). While recent research has focused on the implications of who is interviewed in a household to understand ownership patterns (Kilic and Moylan, 2016), the issue of how reported valuation might also differ across household members has not been considered.

Further, the analysis presented here is based on large nationally (Ecuador and Ghana) and state (for Karnataka) representative surveys. This is an advantage over studies that are either small scale or based on experimental data. The three countries are at different levels of economic development and represent quite different social and cultural environments; thus, the results are likely to be more indicative of a general pattern than would be obtained in a study that simply focuses on one country.

The ability to respond to survey questions on the valuation of immovable property is likely related to the degree of development of real estate markets, and in turn, to the degree of economic development and urbanization. In more traditional, rural societies, ownership of a dwelling may depend more on inheritance of a land parcel rather than on the market, with real estate transactions being less frequent. When people build houses slowly, over an extended period, they may be less likely to know the market value. Further, the development of real estate markets depends on private property rights being widespread. Ecuador is more urbanized (63\% as compared to $51 \%$ and $49 \%$ in Ghana and Karnataka, respectively) and has more well developed real estate markets than either Ghana or Karnataka. Moreover, customary tenure over land, with complex patterns of usufruct rights by an extended family, is much more common in Ghana than in Karnataka or Ecuador. The Karnataka housing market is rapidly developing due to the fast pace of urbanization, greater housing demands driven by increased disposable income and changing needs of the population.

Another differentiating factor among our three countries is in the strength of married women's property rights, which are more favorable to women in Ecuador than in Ghana or Karnataka (Deere et al., 2013). Stronger marital property rights not only benefit women who are currently married, but also increase property ownership by women who are divorced or widowed. In a previous analysis, we found a large gender gap in the incidence of home ownership in Karnataka (42\% for men vs. $16 \%$ for women) and Ghana (30\% vs. 16\%) compared to Ecuador (34\% vs. 36\%) (Doss et al, 2015, Fig. 1). To the extent that property owners are 
likely to be better informed about asset markets and the potential sales value of their properties, we would expect that gender differences in the estimation of housing values would be greater in Ghana and Karnataka than in Ecuador.

To investigate potential systematic biases in reports of housing value, we first consider the housing values reported by the household member(s) identified as the most knowledgeable about household assets, i.e., the primary respondent. To test how likely men and women are to provide values for the assets owned, we compare the share of missing values by sex and type of primary respondent. Only in Karnataka is there a difference in response rates between men and women, with the responses from women more likely to be missing.

Since housing values are likely to vary depending on the size and quality of the dwelling, we undertake a multivariate analysis that controls for asset characteristics while trying to unpack why men and women provide different values of the potential sale price of the dwelling. The results suggest that men and women may estimate the value of specific attributes of the dwelling differently, leading to overall valuation differences. Further, using a semi-parametric decomposition technique that examines the entire distribution of values and not only at the mean, we find that given the same set of housing characteristics, women's values cluster more in the middle of the distribution than men's, while men more often report higher values.

Finally, for a subsample of households in Ecuador and Karnataka, we have valuation data from both members of a couple, thus, we can compare the values provided by husbands and wives for the same dwelling. In Ecuador, when interviewed separately, wives tend to provide values in the middle of the distribution as compared to husbands. In Karnataka, wives more often provide values in the lower half of the distribution while husbands more frequently report values in the upper end of the distribution.

Our results have implications for the interpretation of measures of the gender wealth gaps and suggest that care should be taken in choosing survey respondents. If only men are interviewed, the mean values of housing would not necessarily be different, but we would obtain higher levels of inequality than would be the case if only women are interviewed.

The remainder of the paper is organized as follows. Section 2 briefly discusses the current literature on wealth measures. The data and methods are elaborated in section 3 . The results and the discussion are presented in sections 4 and 5, respectively.

\section{Measuring Wealth}

Household surveys, either multipurpose surveys or specialized wealth surveys, are an important source of information on household wealth. The other key sources are administrative records, including property registries, property tax records, and probate records. Each source has its own set of challenges and may not be appropriate across all country contexts. ${ }^{3}$ Property registries may not be updated or complete. Property tax information is often unavailable and the valuations often use simple formulas that do not take many of the property characteristics into consideration. Probate court records only provide information on a person's wealth at the time of death and only for a very small fraction of the population. Thus, household surveys have become the primary means of collecting data on household and individual wealth. Household surveys also provide a better medium for collecting individual level asset data and linking information on wealth to individual characteristics, such as sex.

The most common approach to collecting asset data in household surveys has been to count the number of assets owned by the household rather than obtain information on asset values. Filmer and Pritchett's (2001) seminal paper firmly established the use of an asset index 
as a measure of household socioeconomic status (SES). Using principal components analysis to develop an asset index, the authors find that the household SES classification using consumption is similar to the classification using the asset index. Their study also suggests that the asset index is a good proxy for material well-being and thus, can be used as such in surveys that do not collect income or consumption data. There is now a burgeoning literature that routinely uses an asset index as an indicator of wealth in analysis of household and individual level welfare outcomes such as health and education (Ainsworth and Filmer, 2006; Schellenberg et al., 2003; Sahn and Stifel, 2003).

The main advantage of using asset indices lies in the ease of data collection as compared to income, consumption, or wealth data. Yet, asset indices provide limited information. While they proxy material well-being at a point in time quite well, they are less useful to identify trends over time or patterns across diverse populations (Harttgen, Klasen and Vollmer, 2013). They do not capture differences in quality, quantity or the age of the assets. Measures of wealth would reflect these differences. Another issue is that the standard set of inequality indicators (Gini coefficient, Lorenz curves, percentile and quantile ratios, wealth shares and so on) cannot be directly calculated using asset indices, limiting comparisons of wealth and income inequality. ${ }^{4}$

Wealth data are more complete as they consider both assets and liabilities and account for the quantity and quality of assets held. Further, standard inequality metrics can be applied to the wealth distribution. Where wealth data is available, comparisons routinely show that wealth inequality is higher than income inequality. For example, an analysis of 26 individual countries finds that the gap between the Gini coefficient for wealth and that for income averages about 30 percentage points (Davies, Sandstrom, Shorrocks, and Wolff, 2008). More recently, analysis of net wealth across 15 European countries shows higher inequality of net wealth when compared to income or consumption (ECB, 2013).

As nationally representative household survey data on asset values become more widely available, we can better analyze how wealth is distributed and how it affects other household outcomes. Yet, we need to identify best practices in collecting such survey data and to understand the biases that may result from different approaches. Ward (2014) discusses two approaches for obtaining measures of wealth through household surveys. One is by matching the list of assets owned by the household with local prices; this is satisfactory only when the assets are standardized and there are local markets for the items. The second is the approach we are using, which is asking the respondents themselves to report the monetary value of their assets. Although self-reporting could be biased, it may reflect subjective well-being and may also influence household behavior along several dimensions (Ward, 2014; OECD, 2013).

In this research, we focus on housing values as our measure for examining differences in valuation by men and women. Housing is a key component of household wealth, and typically dominates the household wealth portfolio, especially as countries become more economically developed and urbanized. In Ghana, the principal residence comprises $27 \%$ of total gross household wealth. In Ecuador, which is much more urbanized, the comparable figure is $62 \%$. The rural-urban patterns are particularly visible in Karnataka, where the principal residence is $25 \%$ of household wealth in rural areas, $53 \%$ in urban areas (excluding Bengaluru) and $79 \%$ in the state capital, Bengaluru.

A second reason to focus on housing values is that it is relatively easy to consider housing characteristics. Thus, we can consider reported housing values controlling for the size and other attributes of the dwelling. The other large component of wealth in developing countries is agricultural land; it is difficult, however, to obtain comparable data on land characteristics 
(Gollin and Udry, 2017). For ease of exposition, we refer to the dwelling and housing interchangeably, noting that this refers only to the principal residence, not all dwellings potentially owned by someone in the household.

\section{Data and Methods}

The Gender Asset Gap Project (GAGP) is a three-country initiative that carried out both qualitative and quantitative research on individual and household asset ownership. Representative household asset surveys were carried out in 2010 in Ecuador, Ghana, and the southern Indian state of Karnataka.

The qualitative fieldwork undertaken in each country included focus group discussions, in-depth interviews of key informants and, in Ecuador, participant observation on men's and women's participation in asset markets and knowledge of prices. This initial work informed the phrasing and ordering of questions in the survey instruments.

The quantitative work had two components. First, a household asset inventory was administered to the primary respondent or the principal couple to collect data on all physical assets owned by household members and the values of each asset. The primary respondent was the person in the household most knowledgeable about assets. A second individual was also interviewed about their individual asset ownership. In Ecuador and Karnataka, the second respondent also provided estimates of the value of key assets, including housing.

In Ecuador, the sample of 2,892 households is nationally representative of rural and urban areas and the major two regional geographic and population groupings of the country (the highlands and coast). A total of 4,668 persons completed the individual questionnaire. In Ghana, the nationally representative survey includes 2,170 households; 3,288 persons answered the individual questionnaire. In Karnataka, a total of 4,110 households and 7,185 individuals were surveyed across the rural and urban areas of nine districts covering all agro-climatic zones of the state.

The literature has used a wide range of monetary value measures. Some surveys ask for the value of an asset if it were to be sold at the time of the interview (the potential sales price), while others ask about the cost of replacing that asset. ${ }^{5}$ Many of the Living Standard Measurement Study (LSMS) surveys only ask about rental values of real estate, from which the present value of a property may be estimated. These different approaches can result in significantly different estimates, particularly if transaction costs put a substantial wedge between selling and purchasing prices.

In this analysis, we use the potential sales price of the dwelling as the reported measure of value. ${ }^{6}$ This measure was used consistently across the three countries and respondents had relatively little difficulty in understanding the intent of the question. The wording of the questions about value was very similar in the three countries; minor variations were based on insights gained in the qualitative fieldwork and the field-testing of the instruments. The question on the potential sale value in the Ghana questionnaire was: "If you were to sell the dwelling today, how much would you receive?" In Ecuador, the question was: "If you were to sell the dwelling today, how much would you receive, including the lot?" In Karnataka, the question was: "If the dwelling were to be sold today, how much money would be received?"

Where the three surveys differ substantively is in the placement of the valuation questions and who was asked to respond to them. In the Ecuador survey, the valuation questions were asked in the household inventory and there are three categories of primary respondents: the primary adult couple interviewed together, the primary man interviewed alone and the primary 
woman interviewed alone. Extensive qualitative fieldwork in Ecuador had revealed that the most reliable responses in households with an adult couple were obtained when they were given the opportunity to discuss the potential asset value and arrive at a consensus on the estimate (Deere and Catanzarite, 2016). Allowing each to share their knowledge and discuss almost always produced an answer by consensus. In the case where only one spouse was present for the inventory, the other was asked about values in the individual questionnaire if s/he was an owner of the asset in question. In this case, two measures of value were obtained for that asset—one from each respondent. ${ }^{7}$

In the Ghana survey, the valuation questions were only asked in the household inventory section and only one person responded to these questions. Thus, there is only one measure of value for the dwelling and that is from the primary respondent. In the Karnataka survey, the valuation questions were asked only in the individual questionnaires. The question about potential sale value was asked to both respondents with the same wording.

If women were systematically less likely to provide responses to questions about housing values, then analyses of wealth would be potentially biased, depending on who was interviewed. Thus, our first step is to consider the percentage of missing observations across the various categories of respondents. In this initial analysis, only the primary respondents are included since this allows for greater comparability across the countries.

We then examine how the dwelling characteristics affect the values reported by men and women. We fit an ordinary least squares (OLS) model separately for men and women and use Fisher's Z transformations to evaluate whether the coefficients are significantly different across these groups. This is similar to an examination of interaction effects among our variables of interest and the type of respondent, except that it is more flexible and does not force equality in the residual error. The dependent variable is the log of the value of the principal dwelling.

Further, we also identify the component of these differences that is explained (due to differences in the housing characteristics) and how much is unexplained (due to gender differences in reporting). This is achieved using the DiNardo, Fortin, and Lemieux (DFL) decomposition technique (DiNardo, Fortin, Lemieux, 1996), which allows us to construct a counterfactual distribution of values to analyze how differences in the distribution of observed dwelling characteristics contributes to differences in values provided (Hirano, Imbens, Ridder, 2003). In other words, we can create a distribution of values for men as if they were reporting on dwellings with the same distribution of characteristics (size, quality, etc.) as women (Sierminska, Frick, Grabka, 2010).

The DFL allows us to decompose a raw group difference in an outcome $y$, in this case the log value of a dwelling, into the portion explained by differences in the distribution of the set of observable characteristics (the dwelling characteristics), which is the covariate effect, and the portion unexplained by these differences, the group effect, interpreted as being due to the gender differences between respondents. This technique is preferred to the more standard OaxacaBlinder (OB) approach, in that it allows us to decompose across the entire distribution of values rather than only at the mean. ${ }^{8}$

To begin, denote the sex of the respondent $S \in\{w, m\}$. Let $Y[V \mid S, X]$ be the conditional expected value function given sex and the set of observable dwelling characteristics, $X$, and $g(X \mid S)$ be the distribution of $X$ conditional on the sex of respondent. Thus, the expected outcome for a given respondent is

$$
Y[V \mid S]=\int Y[V \mid S, x] g[x \mid S] d x .
$$


Our aim is to integrate the conditional expectation of values for one set of respondents over the $X$ distribution of the other set of respondents. We obtain slightly different results depending on whether we choose women's values integrated over men's dwelling characteristics or vice versa. With our data, men tend to have dwelling characteristics outside the range of women's dwelling characteristics and thus more precise estimates are obtained by integrating men's values over women's dwelling characteristics. ${ }^{9}$ Therefore, to construct our counterfactual men, we use

(2) $Y_{m *}[V \mid m]=\int Y[V \mid m, y] g(x \mid w) d x$.

We then decompose the raw group difference into two components, one attributable to the difference in the dwelling, or $X$ characteristics (the covariate effect), and the other attributable to men's conditional expected potential sale value function (the group effect).

(3) $Y[V \mid w]-Y[V \mid m]=\left(Y[V \mid w]-Y_{m *}[V \mid m]\right)+\left(Y_{m *}[V \mid m]-Y[V \mid m]\right)$.

We simplify our notation by denoting $W=Y[V \mid w]$, or women's raw expected outcomes, $M=Y[V \mid m]$ for men's raw expected outcomes, and $C M=Y_{m *}[V \mid m]$, or the counterfactual men's expected outcomes given women's distribution of $X$ dwelling characteristics such that equation (3) becomes simply

(4) $W-M=(W-C M)+(C M-M)$.

The first component on the right-hand side represents the group effect and the second component represents the covariate effect.

In order to circumvent issues related to the OB method, DFL employs Bayes' rule by noting that $g(X \mid w)=\omega_{m} g(X \mid m)$, where the weight $\omega_{m}$ is given by

$$
\text { (5) } \omega_{m}=(\operatorname{Pr}(w \mid X) / \operatorname{Pr}(m \mid X)) \times(\operatorname{Pr}(m) / \operatorname{Pr}(w))
$$

CM can then be written:

(6) $C M=Y_{m *}[V \mid m]=\int \omega_{m} Y[V \mid m, x] g(x \mid m) d x$.

This is the weighted expected value for men's potential sale value where the weight reflects differences in the distributions of dwelling characteristics between women and men respondents.

To construct the weights, we took the following steps. First, we pooled the data for both groups. Then, we ran a logit model to predict the values provided by women based on the set of observable dwelling characteristics, $X$, and saved the predicted probabilities. Finally, we computed the weighting factor for men using (5) above to obtain the estimates for the components of (4) above.

With these equalities, we have decomposed the raw difference between women and men $(W-M)$, into the portion due to the covariate effect $(C M-M)$ and the portion due to the group effect $(W-C M)$. The next step in the DFL is to perform the kernel density estimation (KDE) of 
our raw and counterfactual distributions and examine differences in the resulting probability density functions. ${ }^{10}$

\section{Results}

For Ecuador, there are three categories of primary respondents: individual men, individual women, and the couple answering jointly. For Ghana and Karnataka, the primary respondents were only interviewed individually. Table 1 shows the percentage of values that are missing by category of respondent.

Only in Karnataka, are there statistically significant gender differences in whether a value is provided for the principal dwelling; a greater proportion of women respondents did not provide a value for the potential sales price. In addition, worth noting is that Ghana has significantly more missing values than either Ecuador or Karnataka. One plausible reason accounting for the high percentage of Ghana's missing values is the lack of well-developed housing markets. In addition, in Ghana, there may be a set of complicated arrangements under which people "own" dwellings, making the estimation of the values of the properties more challenging. For example, a family house, or the land on which a house is built, may have many joint owners.

Only those who provided a value are included in the multivariate analysis. One possible concern is that if the nonresponse were correlated with household or individual characteristics, it would introduce a sample selection bias. To test this, we estimate a probit model to examine if non-response is correlated with household or individual characteristics (age, education, employment status, marital status, ownership status). This is a pooled model with sex of the respondent as an independent variable and is estimated only for Ghana and Karnataka. Ecuador has too few missing variables to allow for such an analysis. There are some differences across the countries; in Karnataka, while women are more likely to have a non-response than men, few other characteristics are significant. In comparison, in Ghana, the sex of the respondent does not impact the likelihood of non-response, while being an owner, having some primary education, in wage employment, and living in rural area reduces the non-response rate. The results are reported in Appendix Table A1. In order to check if any of the other characteristics vary by the sex of the respondent, we also estimate the models separately for men and women. However, the results of the separate models show very few significant results across Ghana and Karnataka. The predicted probability of non-response from these models is 0.045 and 0.147 for men and women, respectively in Karnataka. The comparable figures in Ghana are 0.135 and 0.177 for men and women, respectively.

The descriptive statistics for the analytic sample are presented in Table 2. The dwelling characteristics include the location of the household (rural or urban), existence of an ownership document (such as title or deed), the number of rooms (excluding kitchens, bathrooms, garages, or those dedicated exclusively to business), size (in square meters), and an index for housing quality. The housing quality indices are adapted to each country context. They identify the main material used in construction of the walls, floor, and roof. In addition, they each include information on the services available, such as water and sewage. A detailed description of the variables used in the index construction appears in the appendix (See Table A2).

The characteristics of the housing on which they are reporting does differ for men and women. In Ecuador, women respondents are more likely to report on dwellings in rural areas and those that do not have formal ownership documents than men respondents. In contrast, in Ghana and Karnataka, men are more likely to report on dwellings in rural areas. More men report on 
dwellings without formal ownership documents in Ghana; almost all dwellings in Karnataka have such documents. In all three countries, men report dwellings with more rooms, although in Ghana women report on houses with larger area. The mean housing quality index is higher for men in Ecuador and women in Ghana, with little difference in Karnataka. Finally, the mean log of dwelling value is higher for men than women in Ecuador and Karnataka, while the difference is not significant in Ghana. Thus, we cannot simply compare the reported values without considering that the housing characteristics differ.

Table 3 presents the results of the OLS models of factors correlated with reported housing values, run separately for men and women respondents. ${ }^{11}$ There are slight differences in coefficients between the samples of men and women, although the patterns vary across the three countries. ${ }^{12}$ In Ecuador, men provide significantly higher values than women for rural dwellings and values provided by men are more sensitive to the quality of the dwelling. In other words, increasing or decreasing dwelling quality corresponds to a significantly greater change in predicted value for men than it does for women. The model also fits somewhat better for men than for women.

In Ghana, however, the only coefficient that displays a significant difference is weak and is associated with the area in square meters. Like dwelling quality for Ecuador, this suggests that men provide slightly higher values for dwellings of the same size. Karnataka displays a significant difference between men and women with regard to whether or not there are formal ownership documents (most dwellings in Karnataka have such documents); women provide lower values for dwellings without documents compared to men.

Taken together, the evidence suggests, somewhat weakly, that not only do men and women give different values for housing, even after controlling for housing characteristics, but they also value the specific characteristics differently. Thus, changes in the characteristics of housing stock would result in different valuations by men and women. ${ }^{13}$

Table 4 reports the results of the DFL decomposition for each country, identifying the group and covariate effects. ${ }^{14}$ The percent of the raw difference explained by the particular component is presented in parenthesis in the last two columns. Figure 1 presents the results graphically as probability densities for each of the three countries. The figures include plots of the raw difference and both covariate and group effect components.

As shown in Table 4, evaluating only at the mean does not provide a complete picture of the differences in conditional values between women and men. For Ecuador, decomposing at the mean reveals women reporting $22 \%$ lower raw values than men. Of this difference, the CM-M covariate effect explains $102.3 \%$ of the difference, meaning only $-2.3 \%$ is left unexplained by the W-CM group effect. In other words, when men are weighted to have the dwelling characteristics of women, they demonstrate slightly lower mean log values than women and thus, the change due to the shift in covariates is larger than the raw difference between women and men.

Results for Ghana are somewhat similar, with the covariate effect explaining $81 \%$ of the variance in women and men's mean log values. However, in Ghana, women report higher mean log value for dwellings (7.90) than men (7.71). Weighting men to have women's dwelling characteristics increases the mean log value $(+0.16)$ for counterfactual men and closes the bulk of the mean gap in dwelling values. The unexplained group effect accounts for less than $20 \%$ of the valuation difference.

Karnataka differs from the others. While the raw gap is only about half that of Ecuador and Ghana (-0.11), there is little variance explained by the differences in dwelling characteristics (approximately 11\%). Instead, the bulk of the gap is left unexplained as a group effect. That is, 
differences in the distribution of dwelling characteristics between women and men do not explain much of the raw mean difference between women and men's reported values in Karnataka. However, if we examine outcomes at the $10^{\text {th }}, 50^{\text {th }}$, and $90^{\text {th }}$ percentile, or view the probability density functions in Figure 1, we see that drawing conclusions from only a mean decomposition might be misleading.

Consider the first panel in Figure 1 and compare it with Ecuador's results for the $10^{\text {th }}$, $50^{\text {th }}$, and $90^{\text {th }}$ percentiles in Table 4 . This demonstrates that the impact of dwelling characteristics and the unexplained group effect differs across the distribution. The density of CM is greater than the density of women at both the lower and upper tails of the distribution and less in the middle range of the distribution. This implies that the group effect for women is such that they tend to report values clustering in the middle of the distribution relative to men for dwellings with the same characteristics. In other words, adjusting for the characteristics of the dwelling, there is an unexplained tendency for women to report relatively higher values than men at the lower tail of the distribution and relatively lower values than men at the upper tails. The impact of the unexplained group effect changes from $-350 \%$ at the $10^{\text {th }}$ percentile (women reporting higher values relative to men) to about zero at the $50^{\text {th }}$ percentile and then reversing to $62.5 \%$ at the $90^{\text {th }}$ percentile (women reporting lower values relative to men).

Women in Ghana also tend to cluster in the middle of the distribution relative to men. Similar to the Ecuador findings, the amount of the raw difference between women and men that is unexplained and due to group effects differs across the distribution. Adjusting for difference in dwelling characteristics closes some of the raw gap across the distribution but still leaves $60 \%$ unexplained at the $10^{\text {th }}$ percentile, $33.3 \%$ at the $50^{\text {th }}$ percentile, and nearly $86 \%$ at the $90^{\text {th }}$ percentile. Therefore, like in Ecuador, there is an unexplained group effect for women suggesting they give higher values for the least valued dwellings and lower values for the greatest valued dwellings relative to men, after adjusting for dwelling characteristics.

Once again, for Karnataka the pattern differs. The raw gaps are smaller throughout the distribution than they were in Ecuador (except for the $10^{\text {th }}$ percentile) or Ghana. However, similar to Ghana and Ecuador, the potential sale price values reported by women tend to cluster in the middle of the distribution, albeit in a truncated range (between log market values approximately 7.7-8.9). The line for CM maps almost perfectly onto the men's raw distribution. In other words, there appears to be only a very slight difference in men's raw values and those if men shared the dwelling characteristics of women. The bulk of the raw difference appears due to the unexplained group effect. We must bear in mind that even slight changes in values may explain a relatively large percent of the difference because raw differences between women and men in Karnataka are quite small throughout the distribution. Across the $10^{\text {th }}, 50^{\text {th }}$, and $90^{\text {th }}$ percentiles we see that there is approximately $50 \%, 50 \%$, and $100 \%$, respectively, of the raw difference that is unexplained and due to the group effect. Like Ecuador and Ghana, there is evidence that women may be reporting lower values relative to men for the most valuable dwellings. Unlike Ecuador and Ghana, it appears women in Karnataka may also be reporting lower values than men for the least valuable dwellings as well (those below approximately 6.7 in log market value).

Overall, Figure 1 reveals similarities across countries. In particular, W-CM, the group effect, tends to be negative in the tails and positive in the middle of the distribution, with the greatest magnitude in the middle of the distribution. In all three countries, women tend to cluster in the center of the distribution compared to men when adjusting for dwelling characteristics. 
For a subsample of households, we have estimates of value for the same property from both members of the couple and thus can compare male and female responses for the same dwelling. ${ }^{15}$ This is the case in Ecuador when the couple was not interviewed jointly. In the individual interview, if the second respondent was an owner s/he was also asked about the value of the property. In Karnataka, the potential sale value was asked of the second respondent if s/he was an owner. Thus, this is a sample of individuals who are owners of the dwelling and thus, expected to be relatively knowledgeable about prices.

Table 5 provides the mean values reported by the sub-samples where both husbands and wives were interviewed separately about the values of the dwelling. It shows that in Karnataka, men and women within the couple sample provide statistically significant different values for the dwelling, with men's valuation exceeding that of women. No statistically significant difference is found for Ecuador.

Again, we consider both the mean differences in values and the distribution of responses by husbands and wives. In particular, we are interested in whether the differences are larger at either end of the distribution of values. In other words, are we more likely to get differences reported in values for dwellings that are either high value or low value?

Figure 2 provides the kernel density estimates for the value of the dwelling reported by husbands and wives in Ecuador. There is little difference in the reported values. Women cluster slightly more towards the middle of the distribution than men. For Karnataka, figure 2 tells quite a different story. Women cluster much more in the lower tail of the distribution, while men systematically report higher values.

\section{Conclusions and future research}

Household surveys are increasingly an important avenue of information on wealth data. Yet, there is little research on identifying the factors that influence the data generation process. This paper poses the important question of whether there are systematic differences by sex in the valuation of housing. Our results provide a nuanced answer. First, the patterns of missing responses regarding housing values is not consistent across countries. We found a gender bias only in Karnataka, where men were more likely than women to report a housing value when asked.

Second, decomposition analyses of the housing values reported by men and women indicate that it is useful to look beyond the mean value as there are important differences across the distribution. Using the responses given by the individual identified as the most knowledgeable about household assets, we compare the values given by women with estimated values of what men would provide if they had dwellings with the same distribution of characteristics as women. The main result common to the three countries is that women's responses are more clustered toward the middle of the distribution. This finding also holds true even when men and women are reporting on the same dwelling in our analysis of values provided by spouses who were interviewed separately in Ecuador and Karnataka.

Differences in reporting by sex will affect our understanding of the wealth distribution. If, for example, a greater proportion of women are interviewed (potentially because men are migrating out of the area), our results suggest that this might lead to calculations of lower wealth inequality than if a greater proportion of men were interviewed. In addition, projects that are targeting the asset poor might identify different households as below the threshold depending on who was reporting asset values. 
Our results also have implications for survey protocols. The recent OECD (2013) guidelines discuss the relevance of choosing the appropriate household reference person to answer valuation questions (and how to substitute for him/her). They note that considering the respondent characteristics may be important. Yet, while they note education, age, and occupation of the respondent as relevant characteristics, they do not include sex.

Differences in valuation related to the sex of the respondent also cast doubt on the traditional practice of analyzing households by the sex of the head (where sole female headed households are compared to those that have a sole male head as well as those headed by a couple). Some of the differences between male-headed and female-headed households may be driven by structural factors, but some may be due to the sex of the respondent. The research presented here cannot claim to fully explain why such differences exist between men and women, but provides a cautionary note for researchers and policy makers who work with such data.

This work should serve as a substantive reminder that the values on assets or incomes reported in economic surveys are not objective facts so much as the subjective opinions of respondents that may be influenced by a host of personal attributes and the social and cultural environment. The structure of the survey, who is asked, what is being asked, may all have unmeasured impacts and introduce unknown amounts of error. This is true whether or not the survey is designed to address gender issues.

Moving forward, survey designers need to be aware that who they interview will affect the responses that they obtain. Our research indicates the need for more systematic work, across contexts, on how who is interviewed within the household influences the results. We encourage researchers to collect data on the value of assets from multiple people including both men and women within the household to further explore the extent to which different individuals provide different answers. In addition, this approach will allow analyses of how their responses are related to important household outcomes, such as consumption, education, and investment decisions. In any surveys where multiple household members are already being interviewed, there is little additional cost to ensuring that questions on the valuation of assets are asked of all appropriate respondents.

When it is not possible to interview multiple people per household, due to budget or other constraints, the choice of the respondent must be given explicit consideration. We find that even when the person interviewed is the one identified as the person who knows the most about household assets, there are gender differences in the reported values. For indicators of women's empowerment or bargaining power, it would be important to have the value of women's wealth as reported by the women themselves. In sum, our study provides additional evidence that whom one chooses to interview in a household survey will affect the results. Yet it is important not to generalize based on findings from a single country. Our results suggest that the direction of the difference-whether women systematically undervalue their assets and men overvalue them-will vary across contexts, and perhaps by the specific asset under consideration. 


\section{References}

Ainsworth, M., Filmer, D. (2006). Children's schooling: AIDS, orphanhood, poverty,and gender. World Development 34 (6), 1099-1128.

Bardasi, E., Beegle, K., Dillon, A., and Serneels, P. (2011). Do Labor Statistics Depend on How and to Whom the Questions Are Asked? Results from a Survey Experiment in Tanzania. The World Bank Economic Review, 25(3): 418-447.

Barsky, R., Bound, J., Charles, K., and Lupton, J. (2002). Accounting for the Black-White Wealth Gap: A Nonparametric Approach. Journal of the American Statistical Association, 97(459): 663-674.

Davies, J. B. (2008). An Overview of Personal Wealth. In J. Davies (ed.), Personal Wealth from a Global Perspective. Oxford University Press and UNU-WIDER, pp. 1-23.

Davies, J.B., Sandstrom, S., Shorrocks, A., and Wolff, E. (2008). The World Distribution of Household Wealth. In J. Davies (ed.), Personal Wealth from a Global Perspective. Oxford University Press and UNU-WIDER, pp. 395-418.

Deere, C.D., and Catanzarite, Z. (2016). Measuring the Intra-Household Distribution of Wealth in Ecuador: Qualitative Insights and Quantitative Outcomes, In F. Lee and B. Conin (eds.), Handbook of Research Methods and Applications in Heterodox Economics. Edward Elgar, pp. 512-534.

DiNardo, J., Fortin, N., and Lemieux, T. (1996). Labor Market Institutions and the Distribution of Wages, 1973-1992: A Semiparametric Approach. Econometrica, 64(5): 1001-1044.

Doss, C. (2006). The effects of intrahousehold property ownership on expenditure patterns in Ghana. Journal of African Economies, 15(1), 149-180. http://doi.org/10.1093/jae/eji025

Doss, C., Grown, C., and Deere, C.D. (2008). Gender and Assets Ownership: A Guide to Collecting Individual Level Data. Washington DC: World Bank, Policy Research Working Paper 4704.

Doss, C. R., Deere, C. D., Oduro, A. D., and Swaminathan, H. (2015). The Gender Asset and Wealth Gaps. Development, 57(3-4), 400-409. http://doi.org/10.1057/dev.2015.10Elder, T., Goddeeris, J., and Haider, S. (2011). A Deadly Disparity: A Unified Assessment of the Black-White Infant Mortality Gap. The B.E. Journal of Economic Analysis and Policy, 11(1): 1-44.

European Central Bank. (2013). The Eurosystem Household Finance and Consumption Survey. Results from the first wave. European Central Bank. Statistics Paper Series. No 2

Filmer, D., \& Pritchett, L. H. (2001). Estimating Wealth Effects Without Expenditure Data - or Tears. Demography, 38(1), 115-132. http://doi.org/10.1353/dem.2001.0003

Fisher, M., Reimer, J. J., and Carr, E. R. (2010). Who Should be Interviewed in Surveys of Household Income? World Development, 38(7): 966-973.

Fletschner, D., and Mesbah, D. (2011). Gender Disparity in Access to Information: Do Spouses Share What They Know? World Development, 39(8): 1422-1433.

Fortin, N., Lemieux, T., and Firpo, S. (2010). Decomposition Methods in Economics. In D. Card and O. Ashenfelter (Eds.), Handbook of Labor Economics (4 ${ }^{\text {th }}$, pp.1-102). Amsterdam, Elsevier North Holland.

Gollin, D., and Udry, C. (2017). Heterogeneity, Measurement Error, and Misallocation: Evidence from African Agriculture. Mimeo, Department of International Development, Oxford University. 
Gornick, J. C., Sierminska, E., \& Smeeding, T. M. (2017). The Income and Wealth Packages of Older Women in Cross-National Perspective, (September), 402-414. http://doi.org/10.1093/geronb/gbn045

Harttgen, Kenneth, Stephan Klasen and Sebastian Vollmer (2013). An African Growth Miracle? Or: What do Asset Indices Tell Us About Trends in Economic Performance? Review of Income and Wealth, Series 59, Special Issue, S37-S61.

Hirano, H., Imbens, G., and Ridder, G. (2003). Efficient Estimation of Average Treatment Effects Using the Estimated Propensity Score. Econometrica, 71(4): 1161-1189.

Jäntti, M, Sierminska, E., \& Van Kerm, P. 2015. Modelling the Joint Distribution of Income and Wealth. IZA Discussion Paper No 9190. Bonn, Germany: Institute for the Study of Labor.

Kilic, T., \& Moylan, H. (2016). Methodological Experiment on Measuring Asset Ownership From a Gender Perspective (MEXA) Technical Report. Washington D.C.

McKenzie, D. J. (2005). Measuring inequality with asset indicators. Journal of Population Economics, 18(2), 229-260. http://doi.org/10.1007/s00148-005-0224-7

OECD (2013). OECD Guidelines for Micro Statistics on Household Wealth, OECD Publishing. http://dx.doi.org/10.1787/9789264194878-en

Sahn, D.E., Stifel, D.C. (2003). Exploring alternative measures of welfare in the absence of expenditure data. Review of Income and Wealth 49 (4), 463-489.

Schellenberg, J.A., Victora, C.G., Mushi, A., de Savigny, D., Schellenberg, D., Mshinda, H., Bryce, J. (2003). Inequities among the very poor: health care for children in rural southern Tanzania. The Lancet 361 (9357), 561-566.

Sierminska, E., Frick, J., and Grabka, M. (2010). Examining the Gender Wealth Gap. Oxford Economic Papers, 62: 669-690.

Ward, P. (2014). Measuring the level and inequality of wealth: An application to China. Review of Income and Wealth, 60(4), 613-635. http://doi.org/10.1111/roiw.1206 
${ }^{1}$ Several studies have considered the relationship of income and wealth in developed countries, including Gornick et al, (2009) who find that among older women in the US and five European countries, the overlap between those who are income poor and those who are asset poor is relatively small. Jäntti et al. (2015) develop tools for analyzing the joint distribution of income and wealth and find substantial variation across countries.

${ }^{2}$ Another recent initiative, launched in 2010, on collecting household wealth data is the Eurosystem Household Finance and Consumption. This is a harmonized data collection effort across 15 European countries and a joint project of the central banks of the Eurosystem (ECB, 2013)

${ }^{3}$ See OECD (2013) for a detailed review of the diverse approaches to collecting household wealth as well as a discussion of their strengths and limitations.

${ }^{4}$ Researchers have generated some inequality measures using asset indices. For example, asset indices have been used to estimate household income using the DHS asset index (Harttgen, Klasen and Vollmer, 2013) and asset indices themselves have been used as a measure of inequality (McKenzie, 2005). But neither of these approaches allows for comparisons of wealth and income inequality.

${ }^{5}$ Davies (2008) refers to the former as the realization value and the latter as replacement value.

${ }^{6}$ We also collected data on the potential rental value of the dwelling and the current cost of constructing such a dwelling. Although some respondents were better able to provide a construction value, there was more confusion regarding what such a value would include, particularly where different materials would be used to build such a dwelling today compared to when it was originally built.

${ }^{7}$ Of the 1,734 cases of homeownership in Ecuador, 36\% correspond to households consisting of a principal couple where they completed the household inventory together and thus provide one joint estimate of asset values; $26 \%$ correspond to households consisting of a principal couple where only one of them completed the household inventory but the other spouse provided separate estimates of values when they were an owner/co-owner; and $6 \%$ correspond to households consisting of a principal couple where only one spouse completed both parts of the questionnaire. The remaining $32 \%$ of these households were headed by a sole male or female where only one person answered both the household inventory and the individual questionnaire. ${ }^{8}$ For a detailed proof of the DFL and how it relates to other decomposition techniques see Fortin, Lemieux, and Firpo (2010).

${ }^{9}$ For a discussion of which group to choose as the reference, see Barsky, Bound, Kofi, Lupton (2002) and Elder, Goddeeris, and Haider (2011).

${ }^{10}$ We obtain these kernel density estimations at points created by parsing the log of potential sale values from the pooled sample into 200 equally sized bins and specifying a Gaussian kernel function.

${ }^{11}$ Number of rooms, square meters, and housing quality have been average centered based on each sample's pooled averages so that the intercept reflects the predicted log of the value for an urban and documented home of average characteristics.

${ }^{12}$ Standardized regression coefficients were compared between groups using Fisher's ztransformation.

${ }^{13}$ We also estimated a series of OLS regressions for each country that included characteristics of the respondents as well as those of the dwelling. Overall, we find that the individual 
characteristics add little explanatory power; it is the dwelling attributes that influence the housing value reported by men and women. These results are presented in Appendix Table A3. 14 The results integrating women's values over men's dwelling characteristics are presented in Appendix Table A4.

${ }^{15}$ In Ecuador, this also includes members in consensual unions. 
Table 1. Descriptive Statistics on Principal Residence, \% missing, by sex of primary respondent

\begin{tabular}{|c|c|c|c|}
\hline Respondent & $\mathrm{N}$ & $\%$ missing & \\
\hline \multicolumn{4}{|l|}{ Ecuador } \\
\hline Male & 273 & 1.8 & \\
\hline Female & 832 & 2.9 & \\
\hline Couple & 622 & 3.9 & \\
\hline Total & 1,727 & 3.1 & \\
\hline \multicolumn{4}{|l|}{ Ghana } \\
\hline Male & 631 & 13.5 & \\
\hline Female & 226 & 17.7 & \\
\hline Total & 857 & 14.6 & \\
\hline \multicolumn{4}{|l|}{ Karnataka } \\
\hline Male & 2,442 & 4.5 & \\
\hline Female & 729 & 14.7 & \\
\hline Total & 3,171 & 6.8 & $* * *$ \\
\hline
\end{tabular}


Table 2. Descriptive statistics for the analytic sample

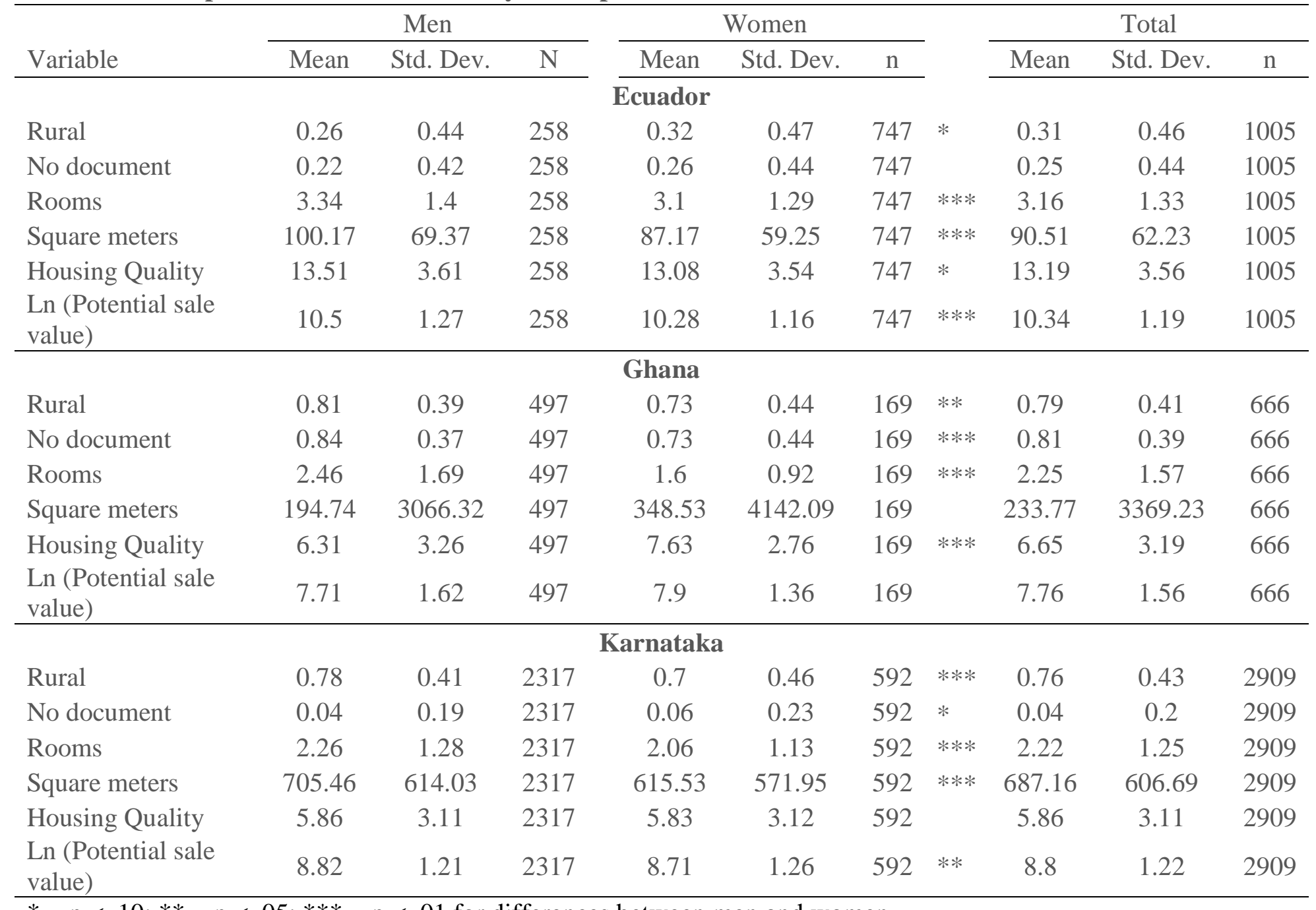

$*=\mathrm{p}<.10 ; * *=\mathrm{p}<.05 ; * * *=\mathrm{p}<.01$ for differences between men and women

Note: Ecuador sample excludes couples responding jointly. 
Table 3. Ordinary Least Squares estimation of factors correlated with natural log value of dwelling by sex of respondent

\begin{tabular}{|c|c|c|c|c|c|c|}
\hline \multirow{2}{*}{ Estimate } & \multicolumn{3}{|c|}{ Men } & \multicolumn{3}{|c|}{ Women } \\
\hline & $\beta_{\mathrm{M}}$ & Std. Error & $\mathrm{p}$ & $\beta_{\mathrm{F}}$ & Std. Error & $\mathrm{P}$ \\
\hline \multicolumn{7}{|c|}{ Ecuador } \\
\hline Intercept & 10.364 & 0.063 & $* * *$ & 10.437 & 0.04 & $* * *$ \\
\hline Rural & -0.011 & 0.122 & & -0.254 & 0.063 & $* * *$ \\
\hline No document & -0.047 & 0.12 & & -0.232 & 0.068 & $* * *$ \\
\hline Number of rooms & 0.096 & 0.039 & $* *$ & 0.163 & 0.026 & $* * *$ \\
\hline Square meters (x100) & 4.154 & 0.777 & $* * *$ & 3.489 & 0.565 & $* * *$ \\
\hline Housing quality & 0.226 & 0.017 & $* * *$ & 0.162 & 0.009 & $* * *$ \\
\hline $\mathrm{R}^{2}$ & \multicolumn{3}{|c|}{0.69} & \multicolumn{3}{|c|}{0.57} \\
\hline $\mathrm{N}$ & \multicolumn{3}{|c|}{258} & \multicolumn{3}{|c|}{747} \\
\hline \multicolumn{7}{|c|}{ Ghana } \\
\hline Intercept & 8.426 & 0.169 & $* * *$ & 8.062 & 0.23 & $* * *$ \\
\hline Rural & -0.379 & 0.164 & $* *$ & -0.002 & 0.203 & \\
\hline No document & -0.511 & 0.172 & $* * *$ & -0.459 & 0.206 & $* *$ \\
\hline Number of rooms & 0.22 & 0.032 & $* * *$ & 0.205 & 0.089 & $* *$ \\
\hline Square meters (x100) & 0.049 & 0.017 & $* * *$ & -0.001 & 0.02 & \\
\hline Housing quality & 0.248 & 0.02 & $* * *$ & 0.263 & 0.034 & $* * *$ \\
\hline $\mathrm{R}^{2}$ & \multicolumn{3}{|c|}{0.47} & \multicolumn{3}{|c|}{0.42} \\
\hline $\mathrm{N}$ & \multicolumn{3}{|c|}{497} & \multicolumn{3}{|c|}{169} \\
\hline \multicolumn{7}{|c|}{ Karnataka } \\
\hline Intercept & 9.321 & 0.044 & $* * *$ & 9.212 & 0.077 & $* * *$ \\
\hline Rural & -0.709 & 0.05 & $* * *$ & -0.673 & 0.093 & $* * *$ \\
\hline No document & -0.173 & 0.101 & $*$ & -0.693 & 0.175 & $* * *$ \\
\hline Number of rooms & 0.205 & 0.018 & $* * *$ & 0.223 & 0.044 & $* * *$ \\
\hline Square meters (x100) & 0.216 & 0.034 & $* * *$ & 0.106 & 0.077 & \\
\hline Housing quality & 0.127 & 0.008 & $* * *$ & 0.144 & 0.016 & $* * *$ \\
\hline $\mathrm{R}^{2}$ & \multicolumn{3}{|c|}{0.41} & \multicolumn{3}{|c|}{0.41} \\
\hline $\mathrm{N}$ & \multicolumn{3}{|c|}{2317} & \multicolumn{3}{|c|}{592} \\
\hline
\end{tabular}


Table 4. Decomposition of differences in natural log value of dwelling, by sex of respondent

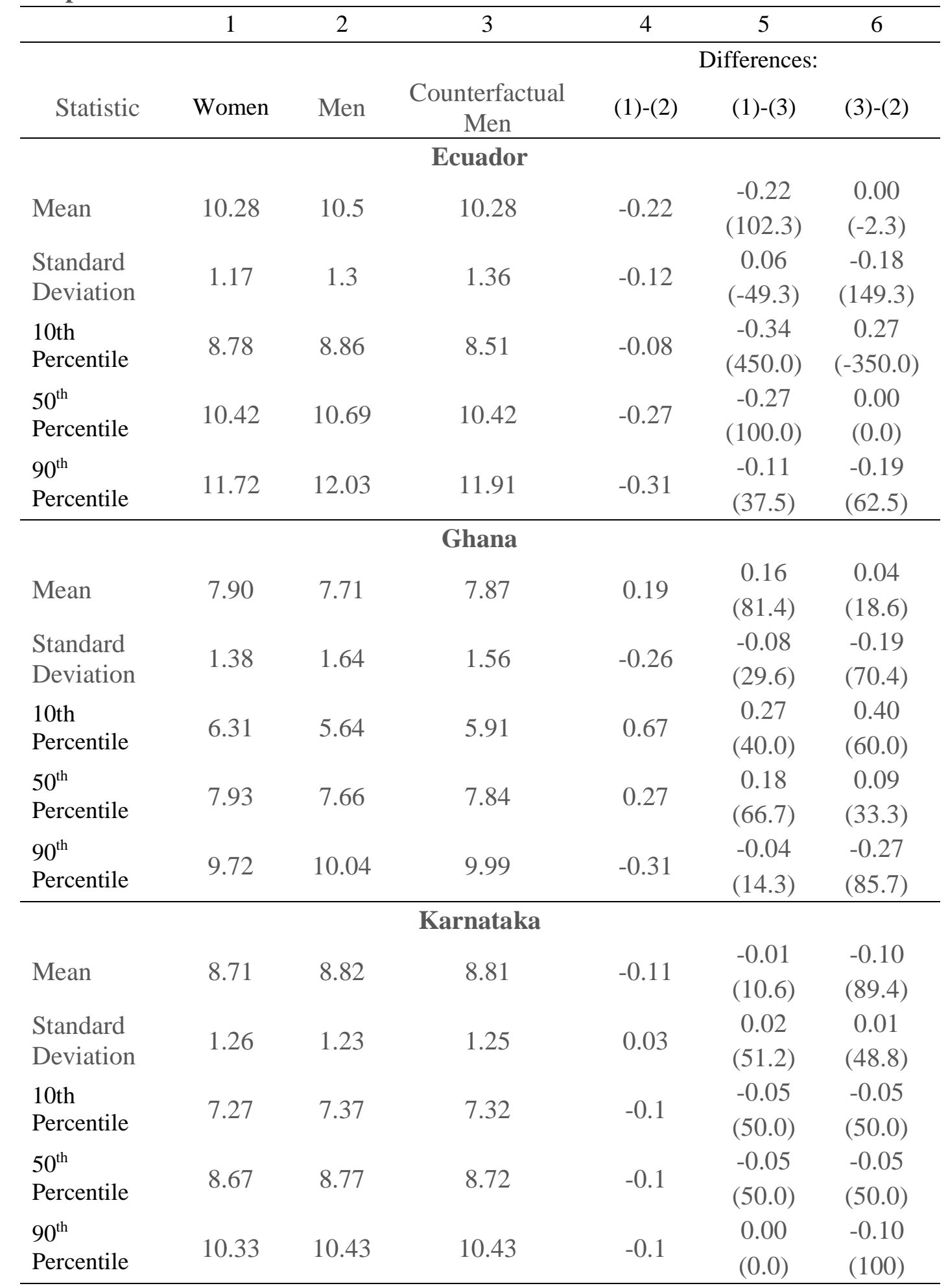

Note: Percent of total variation is provided in parenthesis. 
Table 5. Comparison of means reported by husbands and wives, principal dwelling (PPP values)

\begin{tabular}{lrrr}
\hline & Ecudaor & Karnataka & \\
Man & 57,920 & 19,203 & \\
Woman & 55,429 & 15,450 & $* * *$ \\
$\mathrm{~N}$ & 338 & 1,528 & \\
\hline Note: $* * * \mathrm{p}<.01, * * \mathrm{p}<.05, * \mathrm{p}<.10 ;$ dependent samples t-test &
\end{tabular}


Figure 1. Decomposition Kernel Density Estimates of Log Market Value of Residence

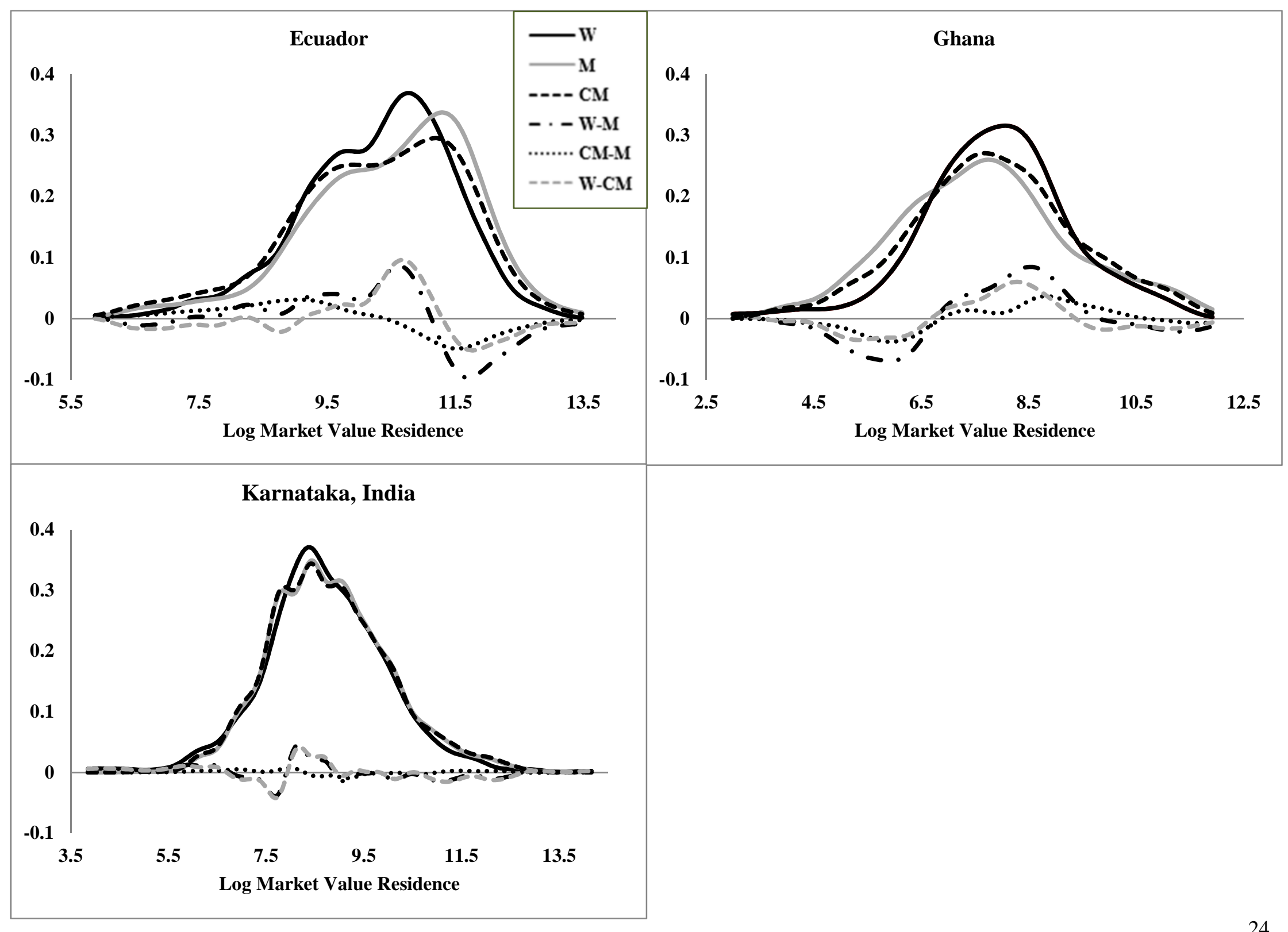


Figure 2. Couples Samples Kernel Density Estimates of Log Market Values of Residences

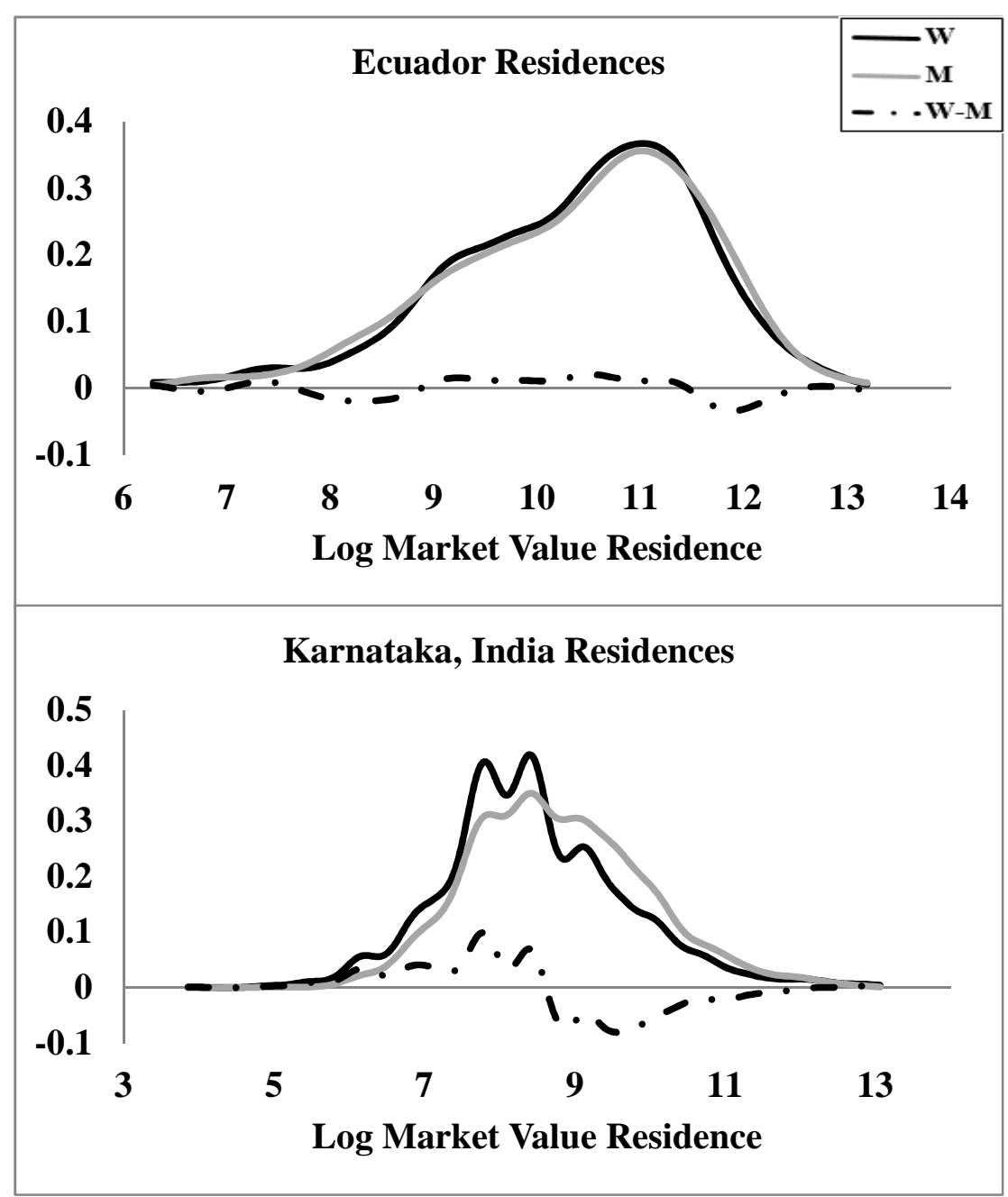


Table A1. Probit Estimates of the Probability of Non-response

\begin{tabular}{llll}
\hline & Marginal effects & Std. Error & p \\
\hline Ghana & & & \\
Owner & -0.158 & 0.061 & $* * *$ \\
Age & 0.002 & 0.001 & $* * *$ \\
Primary and lower secondary & -0.072 & 0.026 & $* * *$ \\
Upper secondary or higher & -0.034 & 0.036 & $*$ \\
Wage employment & -0.067 & 0.039 & $*$ \\
Self-employed & -0.044 & 0.039 & \\
Currently married & 0.032 & 0.031 & \\
Female & 0.027 & 0.035 & $* * *$ \\
Rural & -0.084 & 0.034 & $* * *$ \\
Log likelihood & -333.781 & & \\
Likelihood ratio test Chi ${ }^{2}(9)$ & 43.58 & & \\
N= & 854 & & \\
& & & \\
Karnataka & & & \\
Owner & -0.003 & 0.014 & \\
Age & 0.001 & 0.0004 & \\
Primary education & -0.013 & 0.011 & \\
Secondary education & -0.011 & 0.014 & \\
High Secondary and above & -0.016 & 0.016 & \\
Wage employment & -0.024 & 0.018 & \\
Self-employed & -0.021 & 0.015 & \\
Casual worker & 0.005 & 0.016 & \\
Currently married & -0.001 & 0.013 & \\
Female & 0.077 & 0.019 & \\
Rural & -0.050 & 0.010 & \\
Log likelihood & -726.847 & & \\
Wald test Chi ${ }^{2}(11)$ & 139.18 & & \\
N= & 3,169 & & \\
\hline$*=p<.10 ; * *=p<.05 ; * * *$ & $<.01$ & & \\
\hline
\end{tabular}


Table A2. Reliability analyses of housing quality indices

\begin{tabular}{lccccc}
\multicolumn{1}{c}{ Variable } & Min.-Max. & Mean & Std. dev. & Correlation & N \\
\hline Walls & $0-3$ & 2.65 & 0.88 & 0.44 & 1005 \\
Floor & $0-3$ & 1.35 & 0.56 & 0.5 & 1005 \\
Roof & $0-3$ & 1.67 & 0.92 & 0.4 & 1005 \\
Water source & $0-3$ & 2.64 & 0.85 & 0.63 & 1005 \\
Water location & $0-3$ & 2.43 & 1.01 & 0.71 & 1005 \\
Sewage & $0-3$ & 2.45 & 0.83 & 0.61 & 1005 \\
\hline Scale & $0-18$ & 13.19 & 3.56 & 0.79 & 1005 \\
\hline & & Ghana & & \\
Walls & $0-2$ & 0.92 & 0.84 & 0.61 & 666 \\
Floor & $0-2$ & 0.89 & 0.35 & 0.36 & 666 \\
Roof & $0-3$ & 1.55 & 0.83 & 0.34 & 666 \\
Water source & $0-3$ & 0 s.98 & 1 & 0.41 & 666 \\
Sewage & $0-3$ & 1.1 & 0.88 & 0.43 & 666 \\
Electricity & $0-2$ & 1.2 & 0.97 & 0.52 & 666 \\
\hline Scale & $1-14$ & 6.65 & 3.19 & 0.7 & 666 \\
\hline & & Karnataka & & & \\
Walls & $0-3$ & 1.96 & 1.1 & 0.38 & 2909 \\
Floor & $0-3$ & 0.91 & 0.72 & 0.51 & 2909 \\
Roof & $0-3$ & 1.67 & 0.85 & 0.49 & 2909 \\
Water & $0-1$ & 0.26 & 0.44 & 0.29 & 2909 \\
Sewage & $0-3$ & 1.06 & 1.41 & 0.49 & 2909 \\
Scale & $0-13$ & 5.86 & 3.11 & 0.65 & 2909 \\
\hline
\end{tabular}

The scale reflects increasing quality, with 0 denoting the most inferior. 
Table A3. Ordinary Least Squares estimation of factors correlated with natural log value of dwelling, including respondent characteristics

\begin{tabular}{|c|c|c|c|c|c|c|c|c|c|}
\hline \multirow[b]{2}{*}{ Estimate } & \multicolumn{3}{|c|}{ Ecuador } & \multicolumn{3}{|c|}{ Ghana } & \multicolumn{3}{|c|}{ Karnataka } \\
\hline & $\beta$ & $\begin{array}{l}\text { Std. } \\
\text { Error }\end{array}$ & $\mathrm{P}$ & $\beta$ & $\begin{array}{l}\text { Std. } \\
\text { Error }\end{array}$ & $\mathrm{p}$ & $\beta$ & $\begin{array}{l}\text { Std. } \\
\text { Error }\end{array}$ & $\mathrm{P}$ \\
\hline Intercept & 9.4363 & 0.145 & $* * *$ & 8.111 & 0.402 & $* * *$ & 12.121 & 0.127 & \\
\hline Rural & -0.182 & 0.055 & $* * *$ & -0.451 & 0.134 & $* * *$ & -0.625 & 0.045 & $* * *$ \\
\hline No document & -0.179 & 0.058 & $* * *$ & -0.604 & 0.145 & $* * *$ & -0.286 & 0.086 & $* * *$ \\
\hline Number of rooms & 0.126 & 0.022 & $* * *$ & 0.221 & 0.031 & $* * *$ & 0.179 & 0.017 & $* * *$ \\
\hline Square meters (x100) & 3.463 & 0.452 & $* * *$ & 0.000 & 0.000 & $* *$ & 0.002 & 0.0000 & $* * *$ \\
\hline Housing quality & 0.160 & 0.008 & $* * *$ & 0.135 & 0.016 & $* * *$ & 0.114 & 0.007 & $* * *$ \\
\hline Female & 0.051 & 0.056 & & 0.180 & 0.134 & & -0.002 & 0.057 & \\
\hline Age & 0.011 & 0.002 & $* * *$ & 0.012 & 0.003 & $* * *$ & 0.004 & 0.001 & $* * *$ \\
\hline Owner & 0.079 & 0.067 & & -0.194 & 0.213 & & -0.048 & 0.049 & \\
\hline Currently married & 0.038 & 0.052 & & 0.197 & 0.132 & & 0.065 & 0.055 & \\
\hline Primary & 0.134 & 0.070 & $*$ & & & & 0.018 & 0.044 & \\
\hline Some secondary & 0.241 & 0.080 & $* * *$ & 0.418 & 0.107 & $* * *$ & 0.182 & 0.053 & $* * *$ \\
\hline Secondary & 0.409 & 0.077 & $* * *$ & 0.790 & 0.175 & $* * *$ & 0.372 & 0.066 & $* * *$ \\
\hline Wage employed & -0.029 & 0.055 & & -0.150 & 0.216 & & 0.113 & 0.082 & \\
\hline Self employed & 0.269 & 0.137 & $*$ & -0.417 & 0.158 & $* * *$ & -0.013 & 0.064 & \\
\hline Casual worker & -0.047 & 0.099 & & & & & -0.237 & 0.065 & $* * *$ \\
\hline Adjusted $\mathrm{R}^{2}$ & 0.615 & & & 0.418 & & & 0.431 & & \\
\hline $\mathrm{N}$ & 1,005 & & & 687 & & & 2,907 & & \\
\hline
\end{tabular}

Note: Ghana used two categories for education, basic education (primary and lower secondary, reported here as some secondary) and upper secondary and above (reported as secondary). 
Table A4. Decomposition of women's and men's differences in log potential sales value, counterfactual women

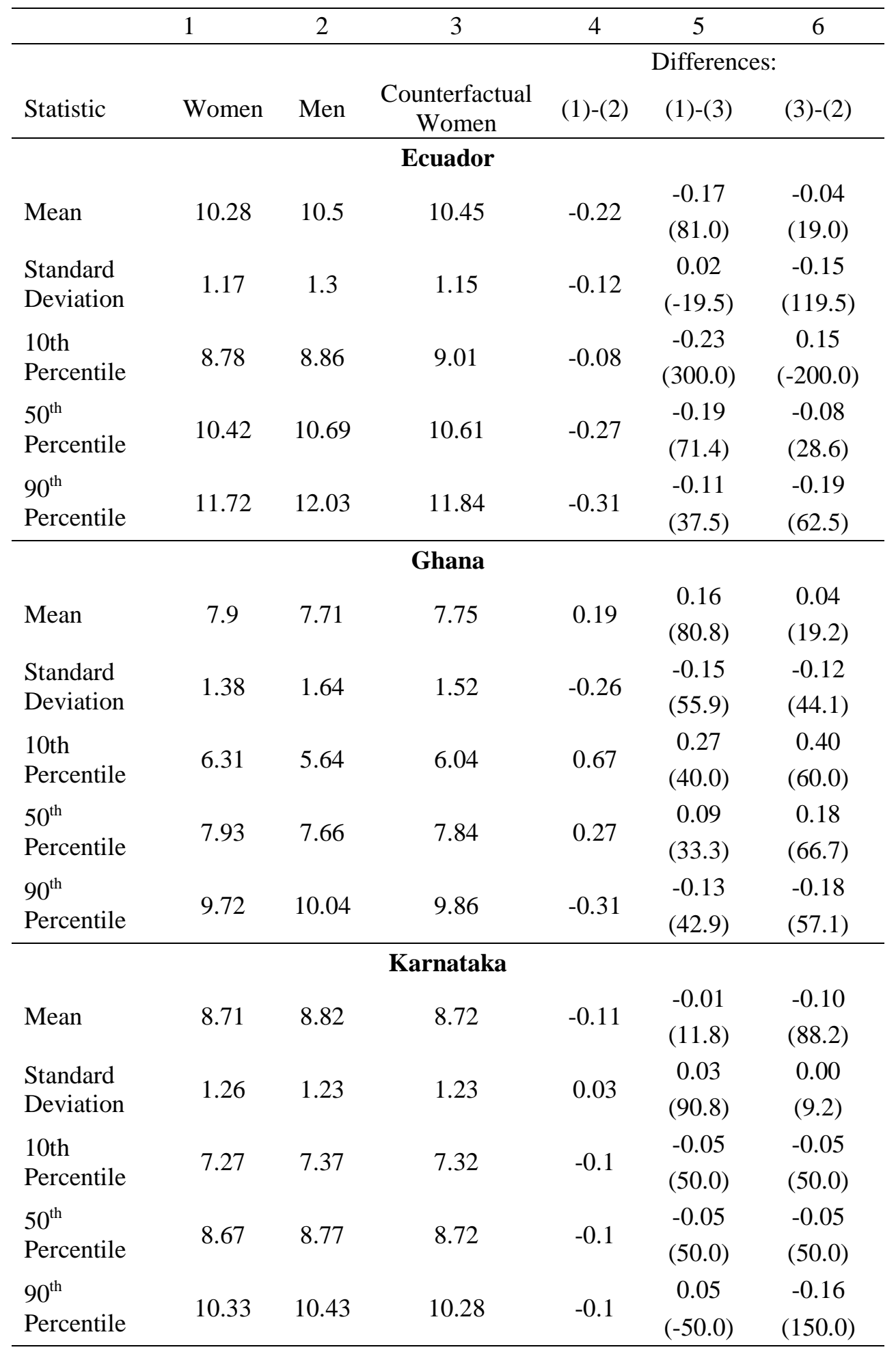

Note: Percent of raw difference explained appears in parenthesis. 